\author{
Maciej Jan KUPCZYK ${ }^{1}$ \\ Jędrzej KOMOLKA ${ }^{2}$ \\ Mariusz JENEK ${ }^{3}$
}

\title{
BADANIA PORÓWNAWCZE WYBRANYCH WŁAŚCIWOŚCI OSTRZY SKRAWAJĄCYCH Z KUTYCH, WALCOWANYCH I SPIEKANYCH STALI SZYBKOTNĄCYCH
}

\begin{abstract}
W artykule w celu wyjaśnienia zróżnicowanych właściwości ostrzy skrawających z konwencjonalnej i spiekanej stali szybkotnącej podczas skrawania stali 40HM-T bez oraz w obecności płynu chłodząco-smarującego przy różnych wartościach prędkości skrawania, przeprowadzono badania weryfikacyjne tych ostrzy dotyczące m.in. ich składu chemicznego, twardości, struktury, objętości olejowej powierzchni oraz współczynnika tarcia. Na końcu artykułu zamieszczono zalecenia co do zakresu stosowalności badanych materiałów narzędziowych.
\end{abstract}

Słowa kluczowe: konwencjonalne i spiekane stale szybkotnące, trwałość, współczynnik tarcia, objętość olejowa powierzchni

\section{Wprowadzenie}

Do materiałów narzędziowych, które wciąż od wielu lat znajdują szerokie zastosowanie podczas wytwarzania narzędzi skrawających pracujących przy umiarkowanych prędkościach skrawania, należy zaliczyć konwencjonalne stale szybkotnące. Podstawową zaletą konwencjonalnych stali szybkotnących jest ich znaczna wytrzymałość na skręcanie i zginanie w porównaniu z innymi materiałami narzędziowymi $[8,9]$. Nie bez znaczenia jest stosunkowo niski koszt ich wytworzenia. W celu poprawy właściwości eksploatacyjnych zaczęto stopniowo zastępować konwencjonalne stale szybkotnące stalami otrzymywanymi w procesach metalurgii proszków. Przy zastosowaniu technologii spiekania w miejsce klasycznej metody hutniczej kierowano się tym, że metalurgia proszków daje większą swobodę w doborze składu chemicznego wyrobu, w który można praktycznie dowolnie ingerować, łącząc składniki nierozpuszczające się wzajemnie,

\footnotetext{
1 Autor do korespondencji/corresponding author: Maciej Jan Kupczyk, Politechnika Poznańska, ul. Piotrowo 3, 60-965 Poznań, tel.: +48 61866527 27, e-mail: maciej.kupczyk@ put.poznan.pl

2 Jędrzej Komolka, Politechnika Poznańska, e-mail: jedrzej.komolka@gmail.com

${ }^{3}$ Mariusz Jenek, Uniwersytet Zielonogórski, e-mail: M.Jenek@ibem.uz.zgora.pl
} 
ze skrajnie różnymi temperaturami topnienia, będące materiałami o różnych wiązaniach chemicznych [1-5, 10-12]. Na właściwości ostrzy ze stali szybkotnących nie wpływa tylko bardziej lub mniej równomierne rozłożenie węglików w ich strukturze, na co często zwracano uwagę w literaturze. Ze wstępnych badań własnych wynika jednak, że w znacznym stopniu odmienna morfologia powierzchni wpływa na zróżnicowane właściwości tribologiczne i w związku z tym ma równie (jeżeli nie bardziej) znaczący wpływ na właściwości eksploatacyjne ostrzy skrawających. Jest to istotne z punktu widzenia określenia uzasadnionego zakresu stosowalności obu odmian stali szybkotnących.

\section{Warunki badań doświadczalnych}

Biorąc pod uwagę powszechność zastosowania stali SW7M, do wykonania ostrzy skrawających zastosowano dwa rodzaje stali szybkotnących o podobnym składzie chemicznym:

- konwencjonalną stal szybkotnącą HS6-5-2 w postaci kutej i walcowanej,

- spiekaną stal szybkotnącą PM6-5-2.

W tabeli 1 przedstawiono orientacyjny skład chemiczny stali konwencjonalnej i spiekanej.

Tabela 1. Orientacyjny skład chemiczny konwencjonalnej (HS6-5-2) i spiekanej (PM6-5-2) stali według obowiązujących norm

Table 1. Approximate chemical composition of the conventional (HS6-5-2) and sintered (PM6-5-2) steels according to obligatory standards

\begin{tabular}{|l|c|c|c|c|c|c|}
\hline \multirow{2}{*}{ Wyszczególnienie } & \multicolumn{7}{|c|}{ Skład chemiczny [\%] } \\
\cline { 2 - 8 } & $\mathrm{C}$ & $\mathrm{W}$ & $\mathrm{Mo}$ & $\mathrm{V}$ & $\mathrm{Cr}$ & $\mathrm{Mn}$ \\
\hline Stal konwencjonalna & $0,8-0,84$ & $5,9-6,7$ & $4,7-5,2$ & $1,7-2,0$ & 4,2 & 0,4 \\
\hline Stal spiekana & 1,0 & 6,0 & 5,0 & 2,0 & 4,5 & 0,3 \\
\hline
\end{tabular}

Do celów badawczych płytki skrawające z konwencjonalnej stali szybkotnącej wykonano z wyrobów hutniczych w postaci kęsów, natomiast płytki skrawające ze spiekanej stali szybkotnącej otrzymano z półfabrykatu handlowego w postaci płaskownika. Oba rodzaje stali użytych do badań były dostarczone w stanie zmiękczonym. Kęsy z konwencjonalnej stali szybkotnącej i płaskowniki ze spiekanej stali szybkotnącej szlifowano do określonej grubości na szlifierce do płaszczyzn. Następnie z tak przygotowanych półfabrykatów wycięto płytki skrawające za pomocą elektrodrążarki drutowej firmy Agiecut model Classic 2. Uzyskano w ten sposób płytki skrawające typu SNUN o kształcie prostopadłościennym, z kątem wierzchołkowym $90^{\circ}$ i wymiarach: $l=9,525 \pm 0,08 \mathrm{~mm}$ oraz $m=1,644 \pm 0,13 \mathrm{~mm}$. Płytki o tej geometrii są przeznaczone do obróbki stali do ulepszania cieplnego, stali nierdzewnych, stopów żarowytrzymałych i miękkich stali o niskiej zawartości węgla. Płytki po wycięciu szlifowano wykańczająco, 
a później polerowano. Starano się, aby uzyskać podobną chropowatość powierzchni płytek z konwencjonalnej i spiekanej stali szybkotnącej, wynoszącą średnio $R a=0,1 \mu \mathrm{m}$, w celu dokonania właściwego późniejszego wnioskowania. Po procesie polerowania płytki skrawające odtłuszczono.

Zakładane właściwości stali HS6-5-2 i PM6-5-2 uzyskano po obróbce cieplnej polegającej na hartowaniu i odpuszczaniu. W celu uzyskania wysokiej twardości, wynoszącej około $65 \mathrm{HRC}$ przyjęto temperaturę austenityzowania $1150^{\circ} \mathrm{C}$, a temperaturę odpuszczania $560^{\circ} \mathrm{C}$. Właściwie dobrana temperatura odpuszczania umożliwia powstanie zjawiska twardości wtórnej. Tak przygotowane ostrza zachowują zdatność do skrawania w podwyższonej temperaturze, bliskiej temperaturze odpuszczania materiału ostrza $[1,4,6,10]$. Ze względu na niską przewodność cieplną materiał stopniowo podgrzewano. Powodem, dla którego cały proces odbył się w próżni, było ryzyko odwęglenia i utlenienia.

Do badań przeznaczono materiał obrabiany w postaci wałków o średnicy $110 \mathrm{~mm}$ i długości $350 \mathrm{~mm}$, ze stali do ulepszania cieplnego 40HM-T o twardości 30 HRC. Jest to gatunek stosowany na odpowiedzialne elementy o dużej wytrzymałości i ciągliwości. Granica plastyczności wynosi $880 \mathrm{MPa}$, a wytrzymałość na rozciąganie $1030 \mathrm{MPa}$. W tabeli 2 przedstawiono skład chemiczny stali 40HM-T [6, 7].

Tabela 2. Orientacyjny skład chemiczny stali 40HM-T (według PN-EN ISO 4597)

Table 2. Approximate chemical composition of the 40HM-T steel (acc. to PN-EN ISO 4597)

\begin{tabular}{|c|c|c|c|c|c|c|c|c|c|}
\hline \multicolumn{10}{|c|}{ Skład chemiczny [\%] } \\
\hline $\mathrm{C}$ & $\mathrm{Mn}$ & $\mathrm{Si}$ & $\mathrm{P}, \mathrm{S}$ & $\mathrm{Cr}$ & $\mathrm{Ni}$ & $\mathrm{Mo}$ & $\mathrm{W}$ & $\mathrm{V}$ & $\mathrm{Cu}$ \\
\hline $0,38-0,45$ & $0,4-0,7$ & $0,17-0,37$ & $<0,035$ & $0,8-1,2$ & $<0,3$ & $0,15-0,25$ & $<0,2$ & $<0,05$ & $<0,25$ \\
\hline
\end{tabular}

Badania zużycia i trwałości ostrzy skrawających prowadzono w procesie toczenia wzdłużnego stali 40HM-T ulepszonej cieplnie do twardości $26 \pm 2$ HRC. Wymienne płytki skrawające mocowano w uchwycie hR 110.16-220. Po zamocowaniu płytki skrawającej w uchwycie uzyskano następującą geometrię: kąt wierzchołkowy $\kappa_{r}=75^{\circ}$, kąt przyłożenia $\alpha_{0}=6^{\circ}$, kąt naroża $\varepsilon_{r}=90^{\circ}$, kąt natarcia $\gamma_{0}=-6^{\circ}$, kąt pochylenia $\lambda_{s}=-6^{\circ}$.

Przyjęto następujące warunki obróbki: materiał obrabiany - stal 40 HM-T, prędkość skrawania $v_{c}=33,75 ; 42,9 ; 59,86 \mathrm{~m} / \mathrm{min}$, posuw $f=0,204 \mathrm{~mm} / \mathrm{obr}$., głębokość skrawania $a_{p}=0,75 \mathrm{~mm}$, skrawanie „na sucho” lub w obecności płynu chłodząco-smarującego. Podczas toczenia stosowano ciecz obróbkową w postaci półsyntetycznej emulsji Statoil Toolway S455N produkcji norweskiej.

\section{Badania doświadczalne}

Najczęściej trwałość ostrza określa się jako czas skrawania do chwili osiągnięcia przyjętej wartości umownego wskaźnika stępienia. Biorąc pod uwagę 
krzywe zużycia uzyskane w badaniach wstępnych oraz dane $\mathrm{z}$ innych publikacji i norm: PN-83/M-58350; PN-ISO 3685, za wskaźnik stępienia przyjęto szerokość pasma zużycia naroża od strony powierzchni przyłożenia $V B_{c}=1,6 \mathrm{~mm}$. Tak jak podano w poprzednim rozdziale, przedmiotem badań zasadniczych były zarówno płytki skrawające ze stali szybkotnących wytworzonych konwencjonalnie, jak i powstałe w procesie metalurgii proszków. Przed przekazaniem płytek do badań przeprowadzono oględziny powierzchni natarcia, przyłożenia i krawędzi skrawającej, tak aby żadna płytka skrawająca nie miała defektów w postaci wykruszeń, wyszczerbień czy pęknięć. Otrzymane na podstawie badań krzywe zużycia pozwoliły na wyznaczenie wartości trwałości ostrzy skrawających dla wskaźnika stępienia $V B_{c}=1,6 \mathrm{~mm}$. Wyniki trwałości ostrzy z konwencjonalnej i spiekanej stali szybkotnącej przy obróbce stali 40HM-T bez płynu oraz z płynem chłodząco-smarującym przedstawiono w tab. 3 .

Tabela 3. Wyniki badań trwałości uzyskane podczas skrawania stali 40HM-T

Table 3. Results of durability investigations obtained during machining of the 40HM-T steel

\begin{tabular}{|c|c|c|c|c|c|c|}
\hline Opis & \multicolumn{3}{|c|}{ Trwałość podczas skrawania na sucho } & \multicolumn{3}{|c|}{$\begin{array}{c}\text { Trwałość podczas skrawania z płynem } \\
\text { chłodząco-smarującym [s] }\end{array}$} \\
\hline$v_{c}[\mathrm{~m} / \mathrm{min}]$ & $v_{1}$ & $v_{2}$ & $v_{3}$ & $v_{1}$ & $v_{2}$ & $v_{3}$ \\
\hline HS6-5-2 & 595 & 266,4 & 141 & 772 & 349,9 & 192 \\
\hline PM6-5-2 & 460 & 286 & 192 & 834 & 599,4 & 336 \\
\hline
\end{tabular}

Badania weryfikacyjne miały na celu określenie przyczyn odmiennego zachowania się (zróżnicowanej trwałości przy różnych wartościach $v_{\mathrm{c}}$ ) płytek skrawających ze stali konwencjonalnej i spiekanej w trakcie toczenia stali do ulepszania cieplnego 40HM-T. Wykonano po 8 pomiarów składu chemicznego konwencjonalnej i spiekanej stali szybkotnącej. Średnie wartości zawartości pierwiastków stopowych nie odbiegały istotnie od podanych w tab. 1 .

Za pomocą mikroskopu skaningowego Tescan Vega 5135 wykonano serię zdjęć zgładów metalograficznych ostrzy z konwencjonalnej i spiekanej stali szybkotnącej (rys. 1). Zdjęcia potwierdziły dużo bardziej równomierne rozmieszczenie węglików w osnowie w przypadku stali spiekanej.

W przypadku konwencjonalnej stali szybkotnącej zakupionej w Szwecji, pomimo dobrego przekucia w celu rozbicia siatki węglików, można było zauważyć, że węgliki nie są równomierne rozłożone i tworzą miejscami pasmowe skupiska, co jest typowym objawem występującym w przypadku stali szybkotnących poddanych walcowaniu, kuciu wydłużającemu lub kuciu wydłużającemu z pośrednim spęczaniem. Zdjęcia powierzchni ostrzy z konwencjonalnej i spiekanej stali szybkotnącej wykonano za pomocą mikroskopu metalograficznego Neophot 32 . Rzeczywisty skład chemiczny ostrzy skrawających sprawdzono za pomocą spektrometru fluorescencji rentgenowskiej - Fischerscope X-ray XDV-SDD Fisher. Przykładowe wyniki tych badań przedstawiono na rys. 2 . 


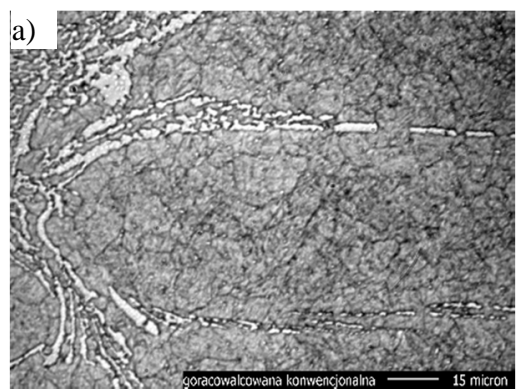

Rys. 1. Obrazy elektronów wtórnych zgładów stali szybkotnącej: a) konwencjonalnej walcowanej na gorąco, b) konwencjonalnej kutej, c) spiekanej

Fig. 1. The images of secondary electrons of: a) conventional hot-rolled steel, b) conventional forging steel, and c) sintered steel
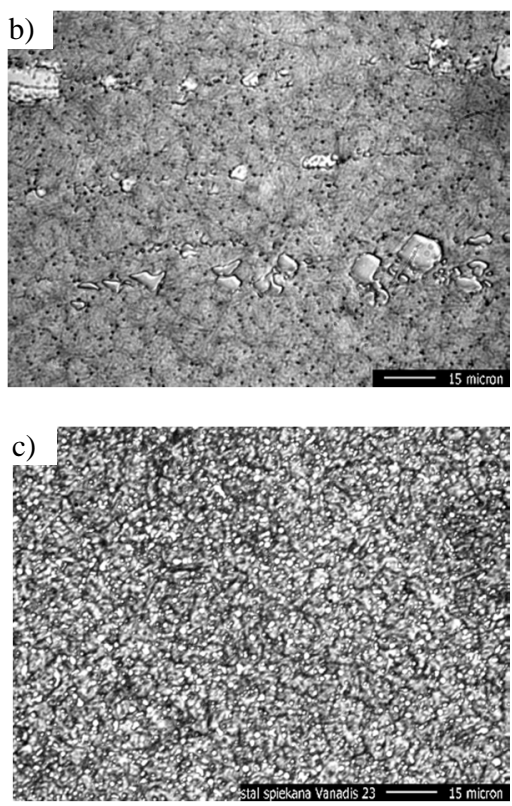

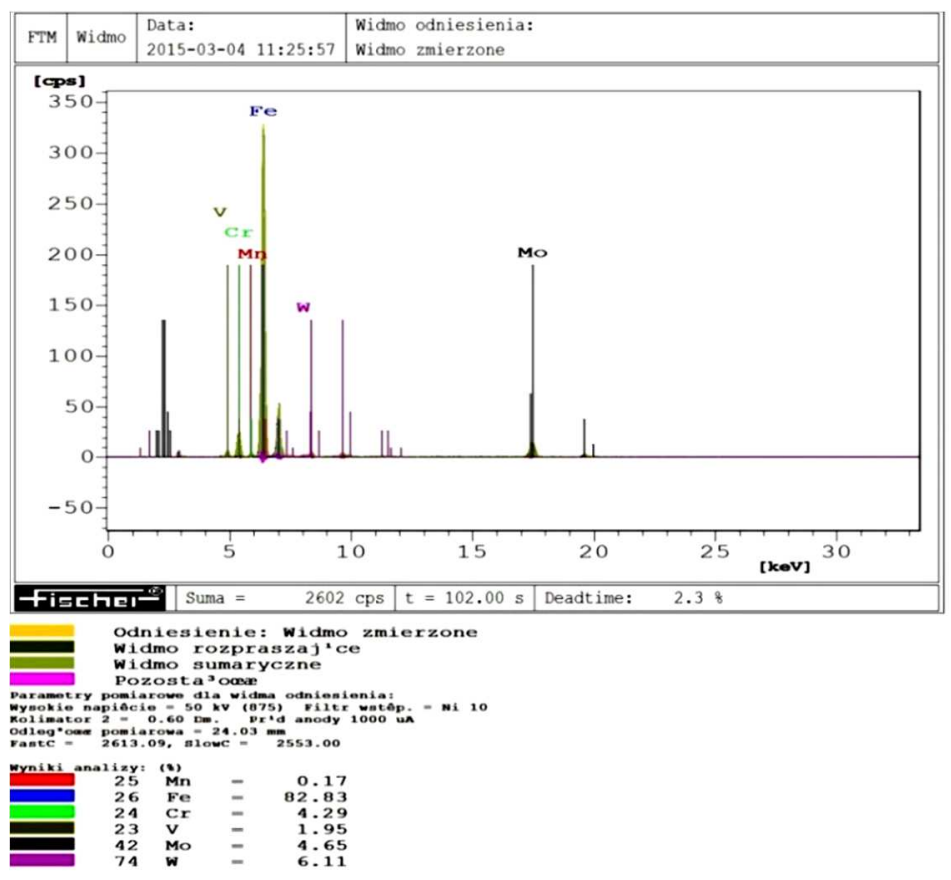

Rys. 2. Przykładowy obraz mikroanalizy składu chemicznego ostrzy

Fig. 2. Exemplary image of chemical microanalysis of cutting edges 
Otrzymane obrazy z mikroskopu wskazują na istotną różnicę w morfologii powierzchni konwencjonalnej i spiekanej stali szybkotnącej. Powierzchnię stali spiekanej tworzą ziarna o ostrych krawędziach, natomiast po walcowaniu i kuciu powierzchnia nie posiada takiej topografii (ziarna są „zlane”, tworząc bardziej ciągłą powierzchnię), mimo że obie powierzchnie mają podobną chropowatość $R a=0,1 \mu \mathrm{m}$. Na rysunku 3 przedstawiono wybrane dane topografii powierzchni oraz krzywe Abbotta dla ostrzy skrawających ze stali: spiekanej, konwencjonalnej kutej oraz konwencjonalnej walcowanej na gorąco.

a)

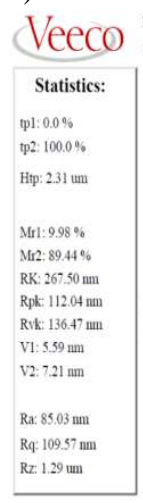

$$
\begin{aligned}
& \text { Mag. } 5.1 \mathrm{X} \\
& \text { Mode: VSI }
\end{aligned}
$$

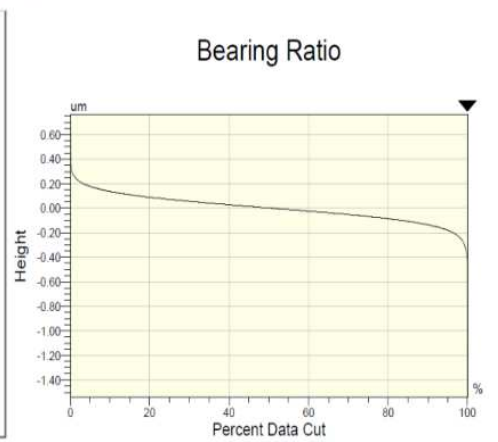

b)

c)
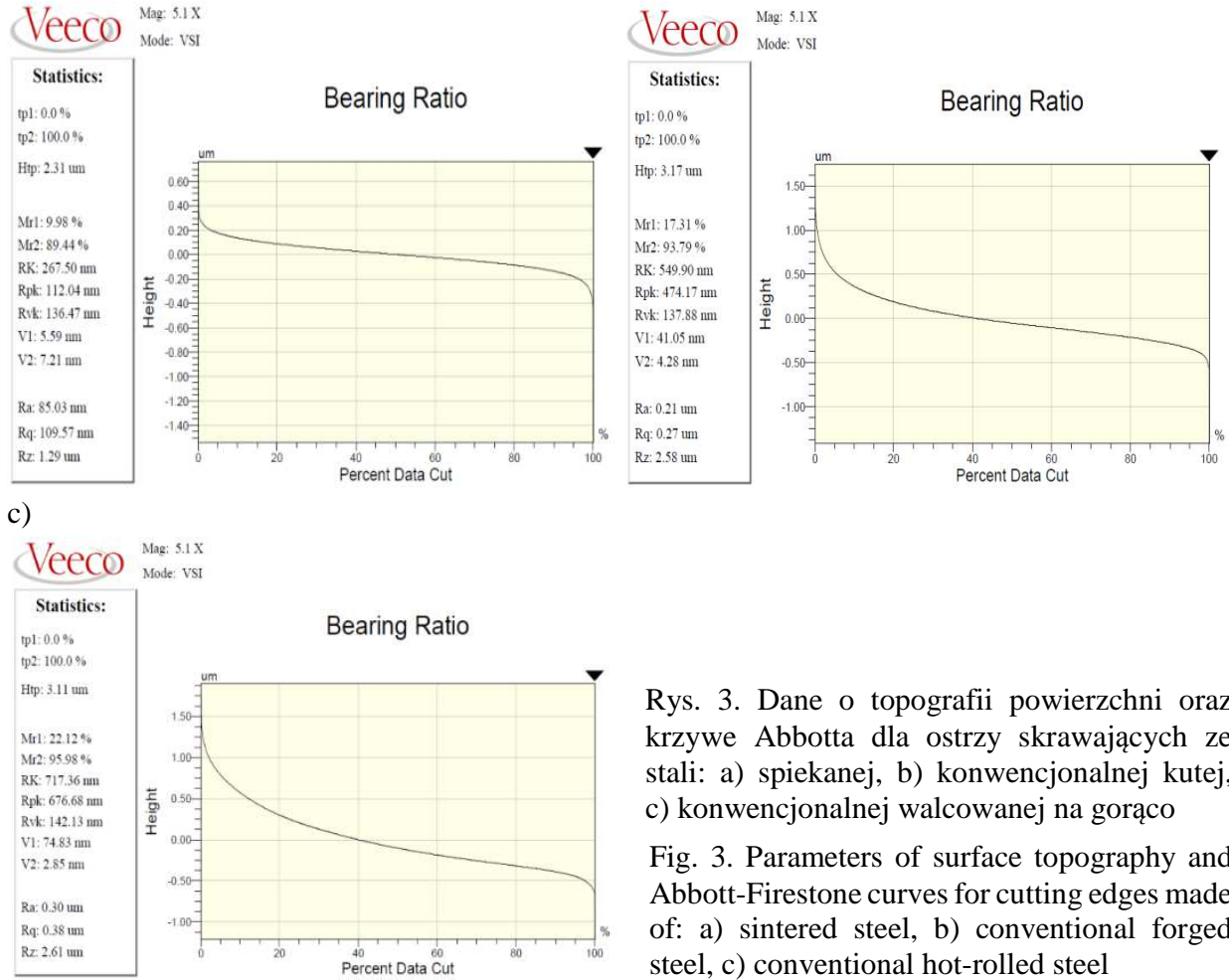

Zmierzone wartości parametrów topografii powierzchni pozwoliły na określenie objętości olejowej powierzchni ostrzy skrawających z konwencjonalnej kutej, konwencjonalnej walcowanej na gorąco i spiekanej stali szybkotnącej. Objętość olejową powierzchni obliczono na podstawie wzoru:

$$
V_{o}=R_{v k}\left(100-M_{r 2}\right) / 2000\left[\mathrm{~mm}^{3} / \mathrm{cm}^{2}\right]
$$

gdzie: $V_{o}$ - objętość olejowa powierzchni,

$M_{r 2}$ - udział materiałowy dla dolnej granicy rdzenia profilu chropowatości,

$R_{v k}$ - wgłębienie powierzchni. 
Parametr $M_{r_{2}}$ określa wartość udziału materiałowego dla dolnej granicy rdzenia profilu chropowatości (odpowiednio $M_{r 1}$ to wartość udziału materiałowego dla górnej granicy rdzenia profilu chropowatości), natomiast parametr $R_{v k}$ opisuje wgłębienia powierzchni. Jest on miarą zdolności eksploatowanych powierzchni ostrza do utrzymywania smaru w istniejących wgłębieniach.

Opisane parametry dają informację o strukturze profilu nierówności, która $\mathrm{w}$ dużej mierze determinuje funkcjonalne zachowanie się ostrza w czasie pracy skrawania [6,7]. Na rysunku 4 przedstawiono wyniki średnich wartości objętości olejowej dla ostrzy skrawających ze stali szybkotnącej: spiekanej, konwencjonalnej kutej i konwencjonalnej walcowanej na gorąco. Na podstawie uzyskanych wyników badań stwierdzono, że mimo wręcz identycznej chropowatości płytek skrawających z konwencjonalnej i spiekanej stali szybkotnącej $(R a=0,1 \mu \mathrm{m})$ różnią się one znacznie pod względem objętości olejowej. Powierzchnia spiekanej stali szybkotnącej charakteryzuje się około 2-krotnie większą objętością olejową od kutej konwencjonalnej stali szybkotnącej, a nawet blisko 3-krotnie większą od walcowanej na gorąco konwencjonalnej stali szybkotnącej.

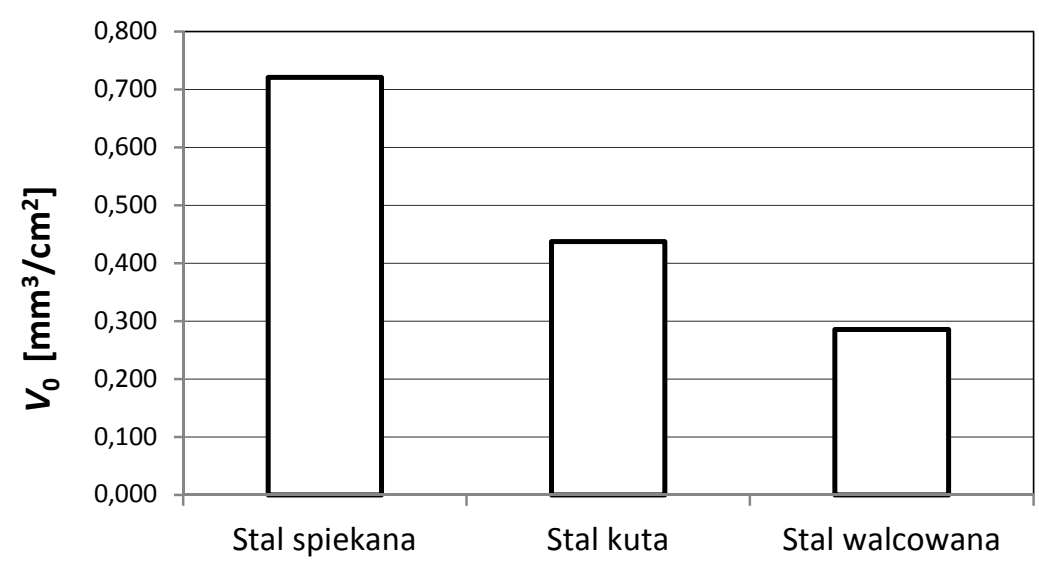

Rys. 4. Średnie wartości objętości olejowej powierzchni dla ostrzy skrawających ze stali szybkotnącej: spiekanej, konwencjonalnej kutej oraz konwencjonalnej walcowanej na gorąco

Fig. 4. Average values of oil volume of surfaces of the cutting edges made of both sintered, conventional forging and conventional hot-rolled high-speed steels

W celu dokonania pełnej interpretacji badań właściwości eksploatacyjnych ostrzy skrawających podczas toczenia stali do ulepszania cieplnego przeprowadzono dodatkowo badania współczynnika tarcia suchego i w obecności płynu chłodząco-smarującego. Podczas badań tribologicznych zastosowano następujące warunki:

- próbka: stal konwencjonalna HS6-5-2, spiekana PM6-5-2,

- przeciwpróbka: stal 40HM-T,

- prędkość obwodowa przeciwpróbki: 27,6 m/min, 
- obciążenie $F: 300 / 400 / 500 / 600 \mathrm{~N}$,

- czas $t: 1200 \mathrm{~s}$ dla tarcia suchego, $2400 \mathrm{~s}$ dla tarcia mieszanego,

- tarcie: suche, w obecności emulsji chłodząco-smarującej Statoil Cimstar MB.

Na rysunku 5 przedstawiono wyniki badań współczynnika tarcia suchego i mieszanego.
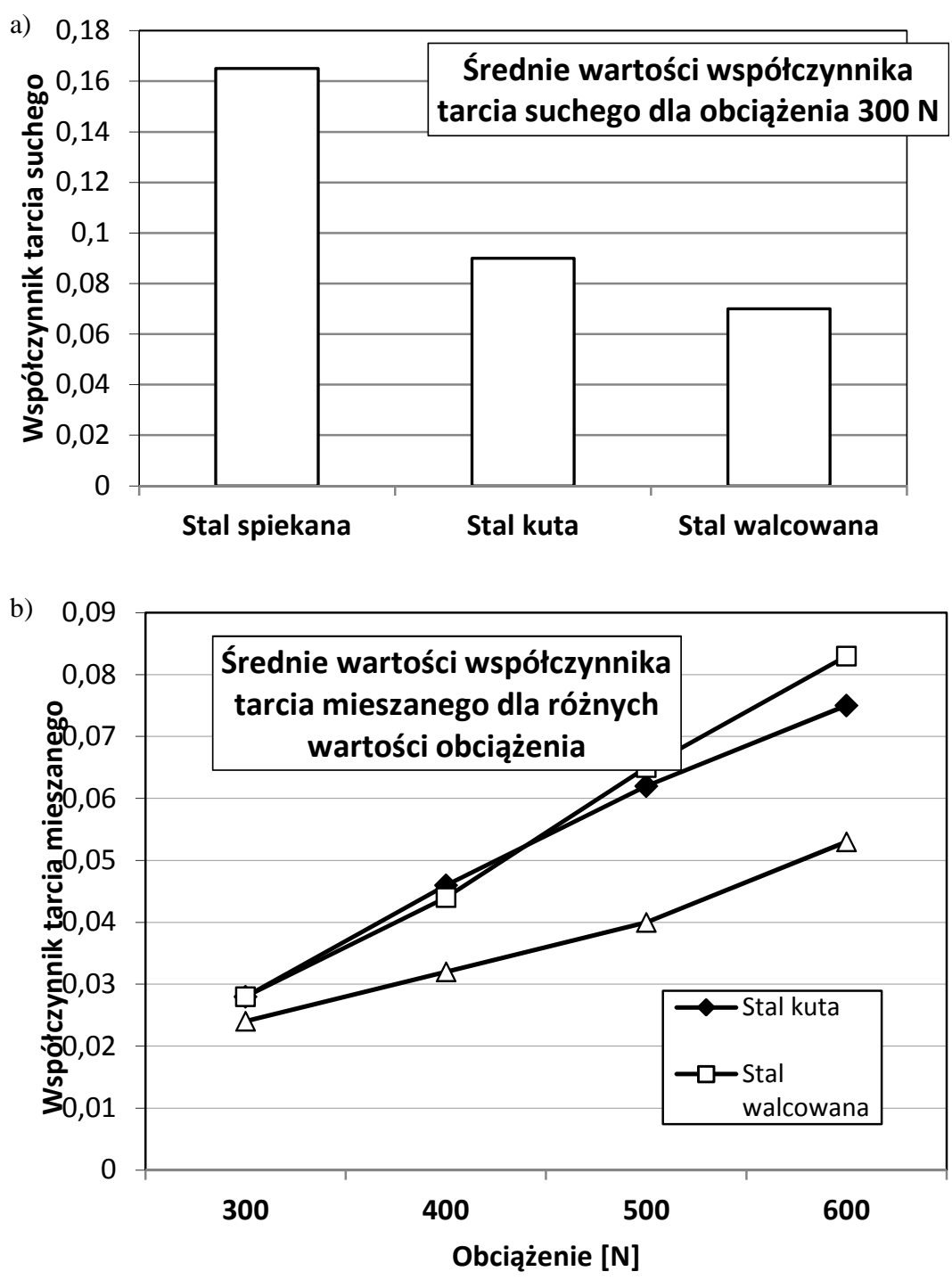

Rys. 5. Średnie wartości współczynnika tarcia stali szybkotnących o stal 40HM-T w warunkach tarcia suchego (a) oraz mieszanego (b)

Fig. 5. Mean values of friction coefficient of high-speed steel against 40HM-T steel at dry (a) and mitigated solid conditions (b) 
Wyniki badań tribologicznych potwierdziły rezultaty trwałości ostrzy podczas tarcia „na sucho” oraz w obecności płynu chłodząco-smarującego, jak też obserwacje obrazów SE z mikroskopu skaningowego.

\section{Wnioski}

Na podstawie przeprowadzonych badań stwierdzono, że:

- ostrza skrawające wykonane ze stali spiekanej wykazują nieco lepsze właściwości technologiczne (np. bardziej równomierny rozkład węglików brak niekorzystnej pasmowości powstającej w procesach kucia lub walcowania konwencjonalnych stali szybkotnących),

- w warunkach skrawania „na sucho” ostrza skrawające z konwencjonalnej stali szybkotnącej przy najmniejszej z zastosowanych prędkości skrawania $\left(v_{c}=33,75 \mathrm{~m} / \mathrm{min}\right)$ charakteryzowały się większą trwałością niż stale spiekane ze względu na korzystniejszą morfologię powierzchni (brak ziaren o ostrych krawędziach, a tym samym mniejsza wartość współczynnika tarcia suchego),

- ostrza skrawające ze spiekanej stali szybkotnącej podczas skrawania z płynem chłodząco-smarującym wykazywały znacznie większą trwałość niż ostrza z konwencjonalnej stali szybkotnącej, ze względu na większą objętość olejową powierzchni, wpływającą na mniejszą wartość współczynnika tarcia o materiał obrabiany.

\section{Podziękowania}

Autorzy składają podziękowanie dr. inż. R. Majchrowskiemu z Politechniki Poznańskiej za pomoc przy pomiarach chropowatości powierzchni.

\section{Literatura}

[1] Bolton J.D., Gant A.J.: Heat treatment of PM HSS metal matrix composites, Proc. European Conf. Advanced PM Materials, Biringham 1995, 1:388-95.

[2] Dobrzański A.: Metaloznawstwo i obróbka cieplna materiałów narzędziowych, WNT, Warszawa 1990.

[3] Dobrzański A.: Podstawy nauki o materiałach i metaloznawstwo. Materiały inżynierskie z podstawami projektowania materiałowego, WNT, Warszawa 2002.

[4] Górski E.: Poradnik narzędziowca, WNT, Warszawa 1989.

[5] Harlin P., Olsson M.: Abrasive wear resistance of starch consolidated and sintered high speed steel, Wear, 267 (2009) 1482-1489.

[6] Katalog firmy Fischer.

[7] Katalog firmy Sandvik.

[8] Kupczyk M.J.: Inżynieria powierzchni - narzędzia skrawające, Wydawn. Politechniki Poznańskiej, Poznań 2015. 
[9] Kupczyk M.J.: Wytwarzanie i eksploatacja narzędzi skrawających z powłokami przeciwzużyciowymi, Wydawn. Politechniki Poznańskiej, Poznań 2009.

[10] Mesquita H.A., Barbosa C.A.: Evaluation of as-hipped PM high speed steel for production of large-diameter cutting tools, Mater. Sci. Forum, 416-418 (2003) 235-240.

[11] Mesquita R.A., Barbosa C.A.: High-speed steels produced by conventional casting, spray forming and powder metallurgy, Mater. Sci. Forum, 496-499 (2005) 244-250.

[12] Zhang G. et al.: Microstructure evolution and mechanical properties of T15, high speed steel prepared by twin-atomiser spray forming and thermo-mechanical processing”, Mater. Sci. Eng. A, 558 (2012) 566-571.

\title{
COMPARATIVE INVESTIGATIONS OF SELECTED PROPERTIES OF CUTTING EDGES MADE OF FORGING, HOT-ROLLED AND SINTERED HIGH-SPEED STEELS
}

\begin{abstract}
S u m m a r y
In this article, to clarify the different properties of cutting blades made of conventional and sintered high-speed steels during machine cutting of 40HM-T steel machined at various cutting speeds and various lubrication conditions, the verification investigations of the blades consisting of chemical composition, hardness, structure, surface oil volume of surface and friction coefficient have been carried out. At the end of the article, recommendations on the range of applicability of the tested tool materials have been included.
\end{abstract}

Keywords: conventional and sintered high-speed steels, durability, friction coefficient, oil volume of surface

DOI: $10.7862 / \mathrm{rm} .2017 .30$

Otrzymano/received:12.07.2017

Zaakceptowano/accepted: 23.09.2017 